\title{
Patch characteristics and domestic dogs differentially affect carnivore space use in fragmented landscapes in southern Chile
}

\author{
Rumaan Malhotra $^{1}$ (D) | Jaime E. Jiménez ${ }^{2}$ (D) | Nyeema C. Harris ${ }^{1,3}$ (D)
}

${ }^{1}$ Ecology and Evolutionary Biology, University of Michigan Ann Arbor, Michigan, USA

${ }^{2}$ Advanced Environmental Research Institute, Department of Biological Sciences, University of North Texas, Denton, Texas, USA

${ }^{3}$ Applied Wildlife Ecology Lab, School of the Environment, Yale University, New Haven, Connecticut, USA

\section{Correspondence}

Rumaan Malhotra, Ecology and Evolutionary Biology, University of Michigan $1101 \mathrm{~N}$. University Ave, Ann Arbor, MI 48106, USA.

Email: rumaanm@umich.edu

Editor: Trishna Dutta

\begin{abstract}
Aim: In an increasingly anthropogenic world, species face multiple interacting threats. Habitat fragmentation and domestic dogs are two perturbations threatening terrestrial mammals globally. Our aim was to determine whether (a) the spatial use of domestic dogs increases with habitat destruction, and (b) domestic dogs and habitat destruction drive the spatial use of native carnivores in a heavily degraded agricultural landscape.

Location: Central valley/Andean foothills transition of Los Lagos, Chile.

Methods: We implemented a camera trap survey in a fragmented landscape comprised of native forest patches amidst a matrix of pastureland. We used single-species occupancy models to assess the impact of domestic dogs and habitat destruction on three mesocarnivores-the foxes, culpeo (Lycalopex culpaeus) and chilla (Lycalopex griseus) and the wild cat güiña (Leopardus guigna). Additionally, we compared temporal activity of all study species including domestic dogs.

Results: Detection rates for both the foxes increased with domestic dog occupancy, while factors driving occupancy differed for each of the native species. We found that a $12 \%$ projected increase in domestic dog occupancy negatively impacted the spatial use of the culpeo. Habitat loss and fragmentation were positive drivers for chilla and domestic dog occupancy. The güiña did not respond to fragmentation and other habitat covariates or domestic dog occupancy. All native carnivore species were primarily nocturnal, while the domestic dog was almost entirely diurnal.

Main Conclusions: We highlight that domestic dog occupancy was positively correlated with habitat loss. Native species showed varied tolerance to domestic dog occupancy and no negative response to habitat destruction. Future conditions of increased fragmentation and habitat loss will likely increase the potential contact between domestic dogs and native carnivores.
\end{abstract}

\section{KEYWORDS}

Canis lupus familiaris, fragmentation, invasive species, landscape, Leopardus, Lycalopex, occupancy

This is an open access article under the terms of the Creative Commons Attribution License, which permits use, distribution and reproduction in any medium, 


\section{1 | INTRODUCTION}

Fragmentation and habitat loss remain a global threat to biodiversity, increasing isolation between habitat patches, with emergent consequences from edge effects (Haddad et al., 2015; Pfeifer et al., 2017). Globally, 70\% of forests are within $1 \mathrm{~km}$ of an edge and are becoming increasingly fragmented, which has resulted in abundances for over $85 \%$ of vertebrates being impacted by edge effects (Haddad et al., 2015; Montibeller et al., 2020; Pfeifer et al., 2017). The negative effects of fragmentation remain highly debated given inconsistent impacts across species and ecological interactions (Fahrig, 2013; Fahrig et al., 2019; Fletcher et al., 2018; Harrison \& Banks-Leite, 2020; Rielly-Carroll \& Freestone, 2017). While species may be able to inhabit edge habitats, they may be excluded via biotic factors such as competition or predation (Michel et al., 2016). Additionally, fragmentation may interact with other factors such as habitat loss, fire prevalence and hunting, making it challenging to ascertain of individual drivers that alter species or their interactions (Bartlett et al., 2016; Bennett \& Saunders, 2010; Cochrane, 2001; Peres, 2001).

Domestic dogs (Canis lupus familiaris, hereafter referred to as "dogs") represent another global threat to biodiversity, as the most abundant carnivore worldwide with a global population estimated at 700 million (Gompper, 2013; Hughes \& Macdonald, 2013). Therefore, dogs are a widespread invasive species that can commonly exploit fragmented landscapes as they more easily permeate from areas of human residence (Broadbent et al., 2008; Oehler \& Litvaitis, 1996; Paschoal et al., 2018). Dogs commonly harass and kill native carnivores, compete for prey species and transmit pathogens to wild populations (Doherty et al., 2017; Laurenson et al., 1998; Vanak \& Gompper, 2009). These disturbances can alter activity patterns and reduce relative abundance of native carnivores. For example, carnivores in Madagascar exhibited spatial avoidance when dogs were present and were more likely to be replaced by dogs in degraded forests near human settlement (Farris et al., 2016, 2017). Similarly, chilla fox (Lycalopex griseus) visits to scent stations in southern Chile were negatively correlated with dog presence, and telemetry data showed that foxes rested in a habitat type that was not preferred by dogs (Silva-Rodríguez, Ortega-Solís, et al., 2010). In general, how dog-wildlife interactions are facilitated by habitat fragmentation and concurrent loss (hereafter referred to as habitat "destruction") is largely unstudied. Furthermore, it is also unknown whether habitat destruction and dogs have similar, opposing or synergistic impacts on carnivores. Given the pervasiveness of both dogs and habitat destruction as major disturbances, it is surprising that few studies have measured and compared their simultaneous effects on native species.

Predicting the effects of habitat destruction on native carnivores, especially in conjunction with dogs, is difficult because our expectations for mesocarnivore response to these two threats (destruction and dogs) may not align. Based on intraguild predation theory, we would expect smaller carnivores such as mesocarnivores to be particularly susceptible to harassment by dogs modulated by body size (Donadio \& Buskirk, 2006). In contrast, for fragmentation and edge effects, a component of habitat destruction, large-bodied mammalian carnivores are particularly susceptible due to their relatively small population sizes, slow growth rates, extended habitat requirements and corresponding home ranges (Schipper et al., 2008). In general, the impacts of habitat destruction on carnivores are harder to predict because many aspects of their ecology such as prey availability and habitat quality are also impacted. Mammals vary in their sensitivity to fragmentation and in their adaptive responses to fragmentation (Crooks, 2002; Janecka et al., 2016; Palmeirim et al., 2020; Smith et al., 2019). For example, a disturbance from fragmentation may shuffle species distributions and facilitate the invasion of non-native competitors or other species (Crooks, 2002; Echeverría et al., 2007; Jessen et al., 2018). Overall, the impacts of fragmentation are even less clear for mesocarnivores, many of which are generalists and have smaller home ranges than their larger counterparts, and thus may be more resistant to or even benefit from fragmentation (but see Crooks et al., 2017; Rocha et al., 2020). Similar to fragmentation, our expectations for the effect of habitat loss on carnivores are not straightforward, and the importance of habitat type may be superseded by intraguild dynamics (Randa \& Yunger, 2006). For example, Massara et al. (2016) found that the occupancy of generalist mesocarnivores was negatively correlated to reserve size throughout the remnant patches of the Atlantic Forest in Brazil, while in an urban-rural gradient in the United States, Randa and Yunger (2006) found that raccoon occupancy increased with residential/ urban habitat rather than forest.

In the Valdivian temperate forest biodiversity hotspot of Chile, both habitat destruction and the presence of dogs are widespread and potentially devastating endemic species (Myers et al., 2000). These forests are being rapidly lost and converted to exotic plantations and pasturelands (Echeverría et al., 2006, 2012). Protected areas are insufficient for meeting goals to maintain the biodiversity value of these forests because protected areas are restricted to the inland Andes rather than to the endemic-rich coastal areas (SmithRamírez, 2004). The central valley, which formerly connected the coastal and montane sections as contiguous forest, has been heavily deforested and is now dominated by cow pastures and exotic plantations (Smith-Ramirez et al., 2010). Today, only small patches of native forests remain as available wildlife habitat that are interspersed throughout this landscape and are privately owned and managed (Figure 1). Free-ranging dogs pose a major threat to the persistence of at least two mammal species of conservation concern, the pudu (Pudu puda, IUCN status of Vulnerable) and the Darwin's fox (Lycalopex fulvipes, IUCN status of Endangered) (Silva-Rodríguez et al., 2016; Silva-Rodríguez, Verdugo, et al., 2010).

Here, we model the effects of habitat destruction, the presence of dogs and their interactions on the spatial use of carnivores. Specifically, we surveyed privately owned forest patches that were outside of protected areas or forestry company ownership using 


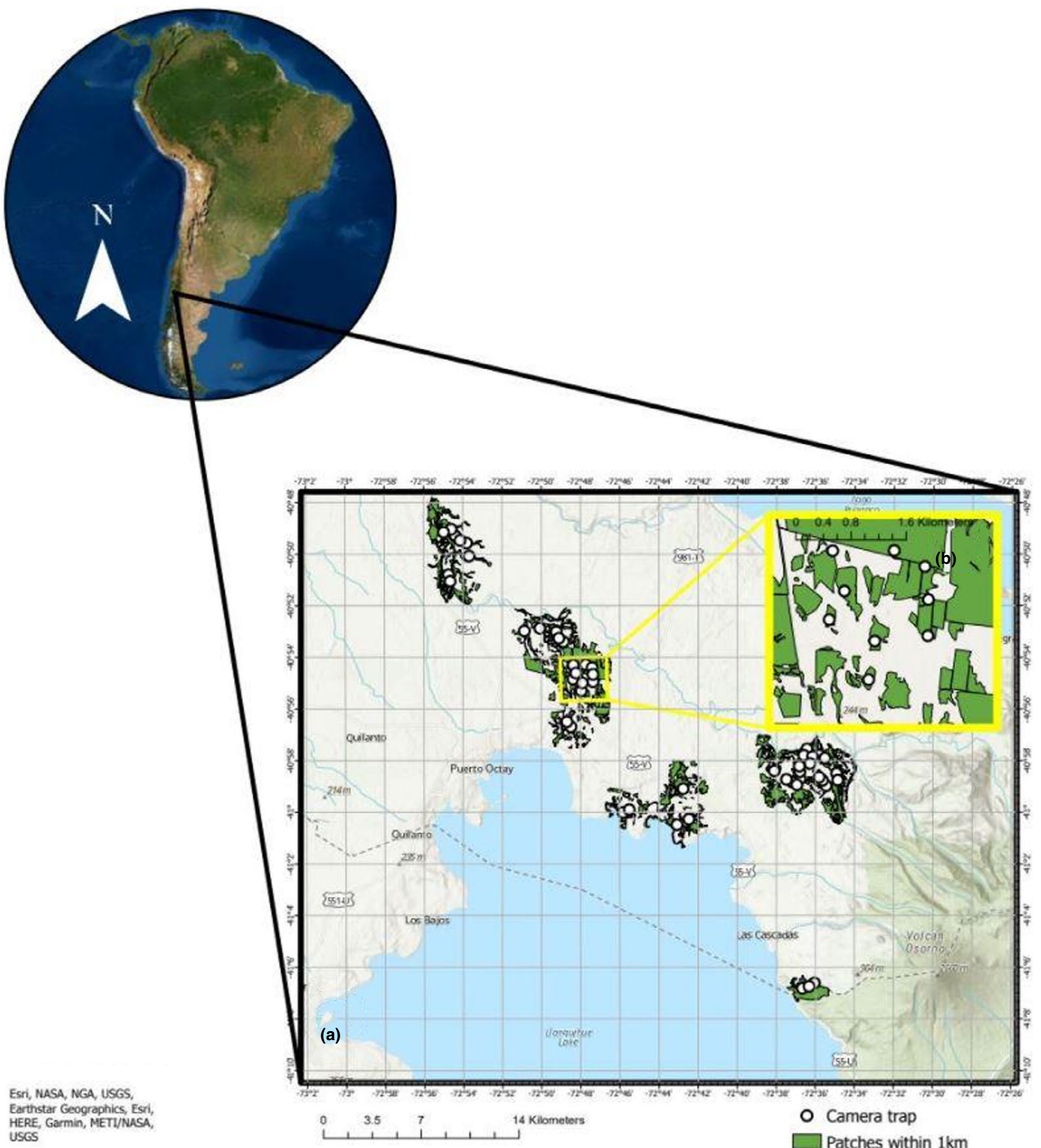

FIGURE 1 (a) Study area located in the Los Lagos Region of southern Chile. (b) Landscape-level distribution of camera deployment throughout patches of native forest straddling the Osorno Volcano. The borders of the box for (b) roughly delineate a 6 sqkm dairy farm, with the cameras placed within the patches of native forest that are interspersed throughout cow pastures

remotely triggered cameras. We expected habitat destruction metrics to be more important than dog space use in explaining the occupancy of forest specialists (e.g. güiña, Leopardus guigna). In contrast, we also expected that in these largely altered landscapes, dog occupancy would be the major driver of native canid spatial use, due to the immediate threat they present, and induced fear effects (Palomares \& Caro, 1999; Vanak et al., 2009; Vanak \& Gompper, 2010). We hypothesized that increasing patch isolation 

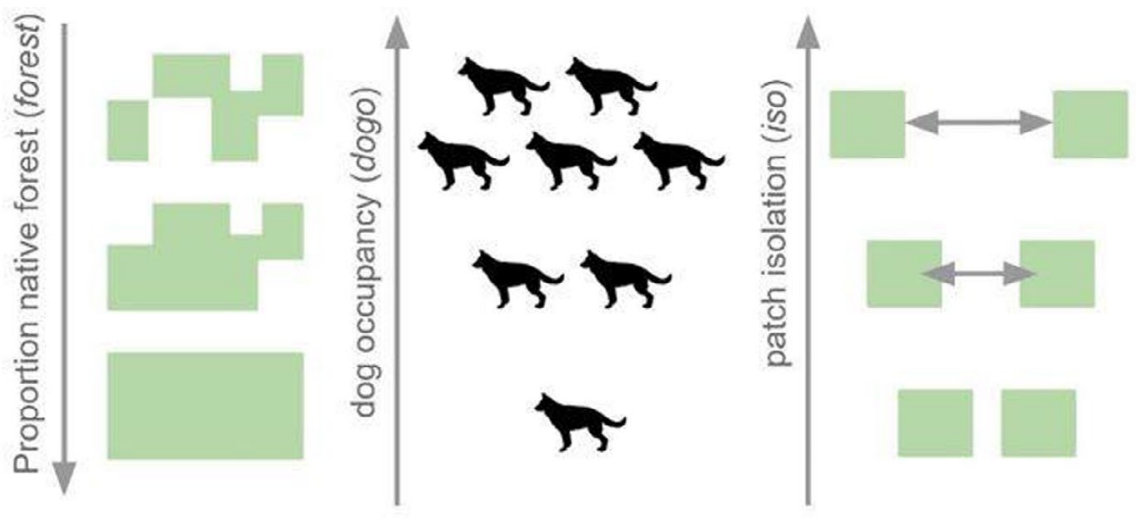

FIGURE 2 Projected facilitation of dog occupancy by habitat loss and fragmentation with expectation that decreasing proportion of native forest and increasing patch isolation would promote higher dog occupancy. Expectations for native carnivore response to fragmentation were opposite to those of dogs, with native carnivore occupancy expected to decrease with decreasing forest and increasing patch isolation
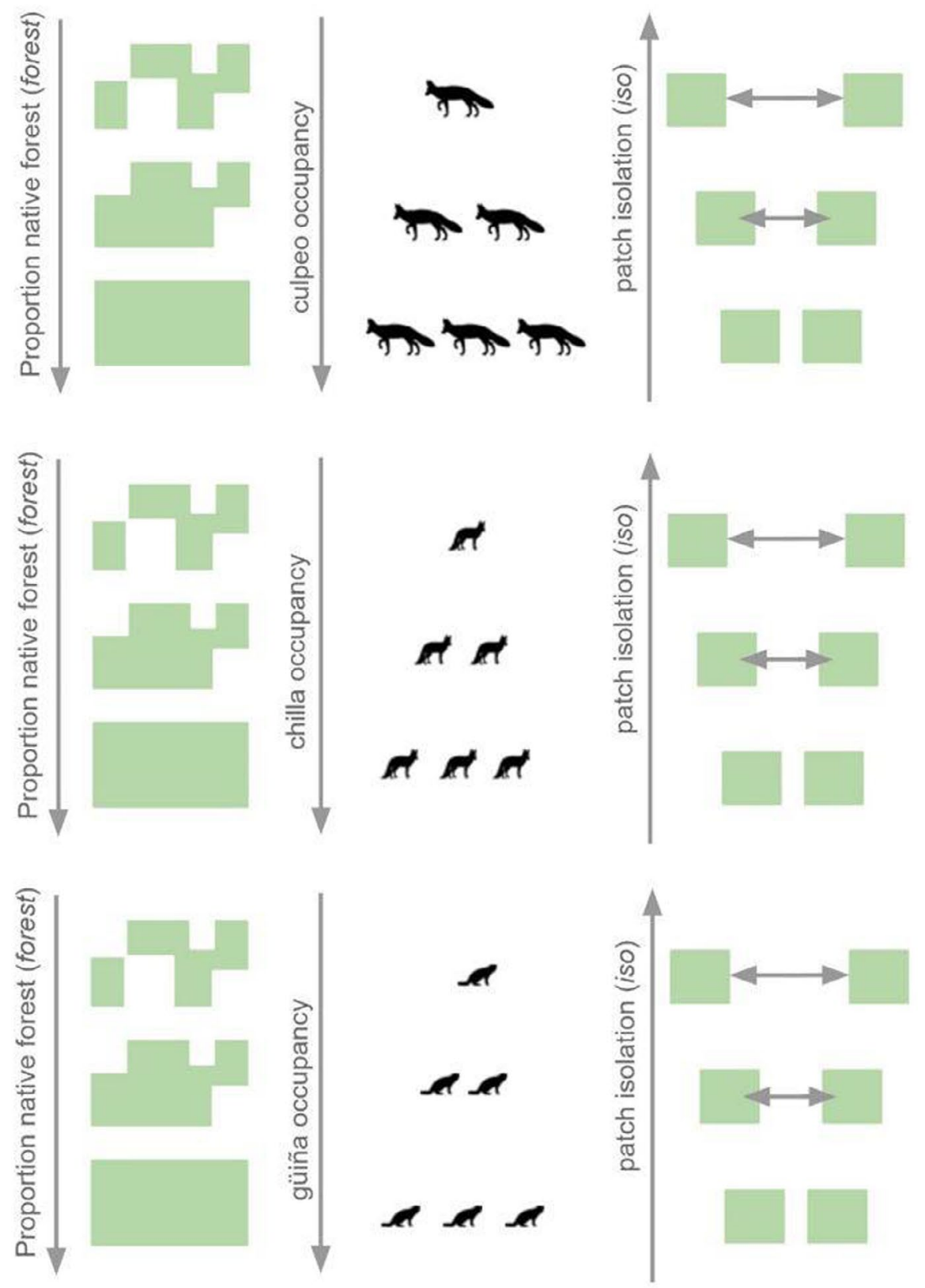

and reducing the proportion of forest would be important drivers

understanding of native carnivore occurrence in the later stages of of dog occupancy, providing evidence that their presence is fahuman-altered landscapes and reconcile the relative contributions cilitated by fragmentation (Figure 2). Our work will enhance our of interacting threats from fragmentation and dog presence. 


\section{2 | METHODS}

\section{1 | Study area}

From mid-May 2019 through the end of August 2019, we surveyed the carnivore community in the Los Lagos region of Chile, near the city of Osorno, between Lago Rupanco and Lago Llanquihue $\left(40^{\circ} 76^{\prime}\right.$ to $41^{\circ} 21^{\prime} \mathrm{S}, 72^{\circ} 54^{\prime}$ to $72^{\circ} 97^{\prime} \mathrm{W}$, Figure 1 ). This area is characterized by Valdivian temperate rain forest (mean daily temperature ranging from 3 to $23^{\circ} \mathrm{C}$ for the year) with a cold, rainy winter season between May and September (1,346 mm annual rainfall) and warm temperate summers (en.climate-data.org). The landscape, formerly dominated by native forest, was at the time of the study dominated by pastures that were used primarily for cattle and plantations of pine (Pinus radiata) and eucalyptus (Eucalyptus globulus) with small remnant stands of native forest. The study area was relatively flat and sandwiched between a large protected area (Parque Nacional Vicente Rosales) on the eastern edge and the Osorno metropolitan area on the western edge. Native forest patches were mostly made up of degraded strips along the edges of pastures comprised of a mix of Lophozonia obliqua, Nothofagus dombeyi, Persea lingue and Laurelia sempervirens with a bamboo understorey (Chusquea quila).

\section{2 | Camera trap survey}

We deployed 50 remotely triggered cameras (Reconyx ( ) PC 850, 900 ) in forest patches throughout the study area during the austral winter, aiming for maximum coverage of areas where we obtained permission. We affixed cameras to trees (minimum diameter $0.25 \mathrm{~m}$ ) with cable locks and placed them $0.5 \mathrm{~m}$ off the ground. We used signs of animal activity such as game trails and scat to determine the specific microsite location of camera placement to maximize species detections. Cameras were placed at least $0.5 \mathrm{~km}$ apart from each other and efforts were made to place them within the core of each patch, if minimum spacing allowed. Each camera was baited with canned mackerel placed inside a bottle with a perforated cap, wired down to keep animals from accessing or removing the bait to maximize detections in a region with low expected carnivore occupancy. Cameras were to set to high sensitivity, one-second lapse between three pictures in a trigger and rapidfire (no quiet period between triggers).

At the end of the survey period, we retrieved images from the cameras and a single observer classified images to the species level. After image identification, we applied a 30-min quiet period to ensure independence of species detections (Mackenzie et al., 2017). These images and the associated site-level environmental variables (explained below) were used to estimate individual species occupancy. We used Moran's I in ArcPro (vers. 2.3.1) and did not find evidence of spatial autocorrelation. We used the "camtrapR" package to organize camera trap images and extract data for modelling (Niedballa et al., 2016) in Program R vers. 3.6.2 (R Core Team, 2019).

\section{3 | Occupancy modelling}

Using single-species single-season occupancy models (MacKenzie et al., 2003), we evaluated the impacts of habitat degradation on the occupancy $(\Psi)$ and detectability $(p)$ of dogs, and evaluated the impacts of habitat degradation and dog occupancy (dogo) on the occupancy and detectability of three focal native species: the chilla, culpeo (Lycalopex fulvipes) and güiña (Figure 3). Covariates for habitat degradation included: proportion of native forest (forest), patch isolation (iso), and understorey (10uds). We also included small mammal trap success $(\mathrm{sm})$ as a coarse measure of prey availability. We first separated species detections into 7-day observation periods and then modelled detection probabilities for each species holding occupancy constant. Finally, we used the best detection models to model the occupancy for each species.

\subsection{1 | Detection covariates}

We modelled detection probabilities with covariates that could increase or decrease the likelihood of an animal being captured on camera if it occupied the vicinity. We measured understorey cover using a point-intercept method, with the understorey height measured every metre for $10 \mathrm{~m}$ in the four cardinal directions surrounding each camera (Karl et al., 2017). We then aggregated values for the understorey cover into three categories: $0 \mathrm{~m}$ (no understorey), $0.25 \mathrm{~m}$ and $0.5 \mathrm{~m}$. Understorey at $10 \mathrm{~m}$ (10uds) is an average of all understorey measurements taken every metre within a $10-\mathrm{m}$ radius of the camera tree (40 measurements per camera site). Understorey was not included in the detection model for the culpeo, as inclusion prevented convergence of the global model. We first modelled occupancy of dogs using habitat covariates (10uds, forest, iso, sm) and then included the resulting site-level estimates as the dogo covariate for native species models (Figure 3). Patches were digitized in ArcPro (vers. 2.3.1) using high-resolution satellite imagery from 2018 (Maxar's Vivid, 0.5-m resolution, 5-m accuracy) to obtain forest, iso and edge estimates. The iso covariate was measured as the mean border-to-border distance to the nearest patch within a 1-km radius of each camera. The edge covariate was measured as the mean ratio of patch perimeter size to patch area for all patches within a $1-\mathrm{km}$ radius of each camera. However, edge was excluded from the final global model, as it was highly correlated with both forest and iso covariates $(R=-0.44,4.23 ; p<.01)$. We estimated $s m$ as a metric of prey availability using the total number of all independent lagomorph, rodent and shrew opossum triggers per camera standardized by the number of trap nights. Camera type (cam) was included to distinguish between white-flash cameras and infrared cameras. Lastly, trap nights (trap), the number of nights an individual camera was operational to collect species detections were included to determine whether sampling effort affected detection rates. Covariates were compared using Pearson's $R$ with a cut-off threshold of $R>0.5$ or $p<.05$. 


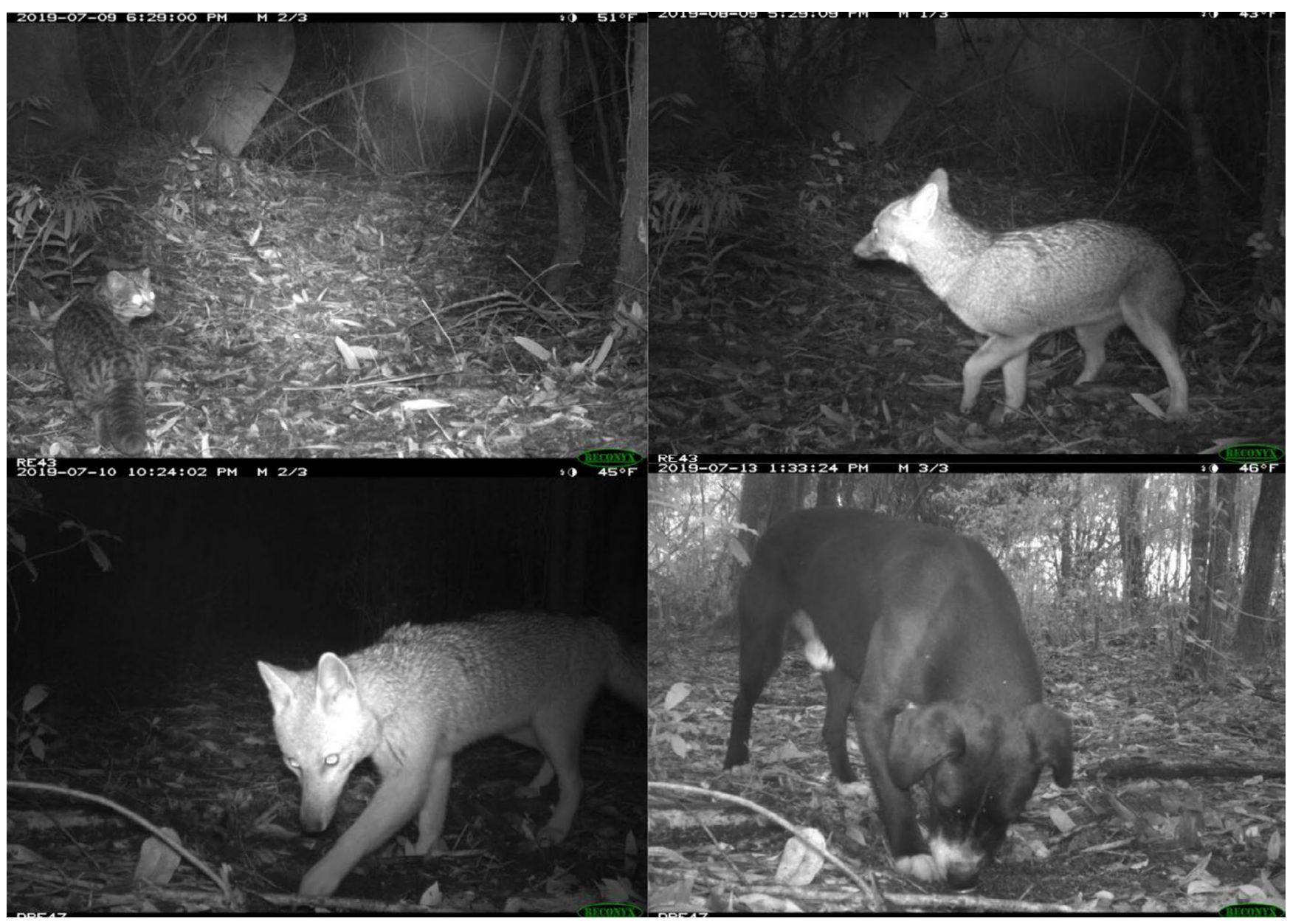

FIGURE 3 Focal carnivores in this study for size comparison of the three native species relative to dogs: the güiña (1.5-3 kg), chilla (2.5$5.5 \mathrm{~kg})$, dog $(10-25 \mathrm{~kg})$ and culpeo $(5-13.5 \mathrm{~kg})$ from top left clockwise. Note that the upper weight range of the culpeo likely represents more southern parts of the range than the study area; they are relatively bigger than chillas and smaller than dogs. Photo credit: R. Malhotra and N.C. Harris, Applied Wildlife Ecology Lab

\subsection{2 | Occupancy covariates}

Occupancy for each species was modelled with dogo and habitat covariates (10uds, forest, iso, sm); edge was highly correlated with forest and omitted from the model. To test whether the impact of dogs on carnivores was facilitated by lack of understorey, we included an interaction term between dogo and 10uds.

\subsection{3 | Model evaluation}

The dog global model included mean understorey height within 10 $\mathrm{m}$ (10uds), camera type and trap night (cam, trap) covariates for detection, while occupancy covariates included understorey (10uds), prey $(\mathrm{sm})$, proportion forest (forest) and patch isolation (iso). Native species global models used the same covariates as the dog model with the addition of dog occupancy (dogo) for detection and an interaction term for dog occupancy and understorey (dogo*10uds) for occupancy. All detection and occupancy covariates were tested for correlation by site using Pearson's R. Model ranking was carried out using the Akaike information criterion, corrected for small sample sizes (AICC), or quasi-AICC (QAICC) if the global model was overdispersed (c-hat $>1.2$ ), with the top model being defined as the one with the lowest AICC or QAICC score. Goodness of fit was tested for all top models $(<2 \Delta$ AICc units or $\triangle$ QAICc units of the highest rank model) using a chi-square statistic. All occupancy modelling was completed in the "unmarked" package (Fiske \& Chandler, 2011) in Program R vers. 3.6.2 (R Core Team, 2019).

\subsubsection{Threshold response to dogs}

We interpreted the $\beta$ coefficient of dogo and confidence intervals not overlapping zero when occurring in top models to conclude significant effects of dogs on carnivore occupancy. When the top models included dogo as a covariate with a non-significant negative coefficient, we determined the threshold level of dog occupancy required for dogo to become a significant negative driver on carnivore occupancy. We incrementally increased the value of the dogo to the maximum occupancy value (1), a single camera at a time. The order 
was determined by ranking cameras from highest to lowest dogo value.

\subsection{Temporal use}

As sympatric carnivores may be more likely to exhibit temporal instead of spatial partitioning to promote coexistence (Santos et al., 2019), we estimated pairwise temporal overlaps for all species and compared the overlap of native carnivore pairs with the overlap of native carnivores-dog pairs. We plotted the temporal activity distributions of each species and determined the degree of overlap between pairs $(\Delta)$ with $95 \%$ confidence intervals generated by 10,000 parametric bootstrap iterations. $\Delta$ values range from 0 indicating completely distinct and non-overlapping temporal activity to 1 indicating complete overlap between the compared species. $\Delta_{1}$ was used for comparisons when one of the species had $<50$ triggers; otherwise, $\Delta_{4}$ was used to estimate temporal overlap between species pairs (Ridout \& Linkie, 2009). We then used the Mardia-WatsonWheeler test to determine whether the temporal patterns varied significantly between individual species, which compares two sets of circular data and determines whether there is homogeneity in the means or variances. We implemented the temporal analyses using the "overlap" and "circular" packages, also in Program R (Agostinelli \& Lund, 2017; Ridout \& Linkie, 2009).

\section{3 | RESULTS}

We detected all three carnivore species over a total effort of 3,500 trap nights. Naïve occupancy estimates for the güiña ( $n=56$ independent triggers), chilla $(n=225)$ and culpeo $(n=39)$ were 0.51 , 0.59 and 0.16 , respectively. Dogs were fairly common $(n=64)$ found at $20 / 49$ camera sites (naïve $\psi=0.41$ ). Additional native carnivores that were detected, although rare, included the chingue (Conepatus chinga, $n=13$ ) and the puma (Puma concolor, $n=4)$. We also detected two additional introduced species: the mink (Neovison vison, $n=20$ ) and domestic cat (Felis catus, $n=21$ ). Darwin's fox was not detected during our camera survey.

\section{1 | Detection of carnivores}

Our study area was comprised of an understorey that ranged from completely open to thickets of dense vegetation, resulting in specific camera sites comprising no understorey to over two metres in height. As such, we expected detection to vary by understorey, depending on species preference on microsite selection for dense vegetation, and the ability of the understorey to reduce the visibility range for a camera trap. For the chilla $(\beta=-6.16, S E=1.38)$ and $\operatorname{dog}(\beta=-7.44, S E=1.84)$, understorey was a strong driver of detection probability, decreasing the detectability for both species (Table 2). For both chilla ( $\beta=1.77, S E=0.37)$ and culpeo $(\beta=3.23$,
$S E=0.834)$, dog occupancy increased detectability. The null model best described güiña detection; that is, no effect of covariates improved model fit.

\section{2 | Occupancy of carnivores}

Overall, modelling occupancy with covariates and accounting for imperfect detection improved our understanding of carnivore space use. Chillas had the highest overall occupancy ( $\psi=0.67$ ), while culpeos had the overall lowest occupancy, but more than doubled from the naïve estimate $(\psi=0.36)$. Güiña was the only species for which the null model was the best model, and the occupancy estimate was thus the same as the naïve estimate $(\psi=0.51)$. In comparison with the native carnivores, dog occupancy was higher than that of the culpeo and güiña, but lower than that of the chilla ( $\psi=0.58$ ).

Factors driving occupancy of carnivores varied by species (Figure 4, Table 1). Despite the importance of understorey for species detection, it did not appear in the best model for any species. It was, however, a negative driver of chilla occupancy in four of 10 top models, which had comparable weights to the best model (Table 1). Given the reliance of mammalian carnivores on prey, unexpectedly, small mammal trap success was important only for the occupancy of the culpeo $(\beta=1.05, S E=0.53)$.

Our work contrasted the ecological consequences of habitat destruction (loss and fragmentation) and dog occurrence on the space use of carnivores (Tables 1 and 2). Habitat metrics were important drivers of chilla and dog occupancy, but did not appear in the model sets for culpeo or güiña. For example, patch isolation was in the top two models for the chilla $(\beta=0.09, S E=0.04$ ) and was positively correlated with occupancy. Proportion of forest did not appear to be important for occupancy of any native species. It was, however, important for dogs ( $\beta=-26.06, S E=12.1$ ), with increasing proportion of forest decreasing dog occupancy. Dog occupancy appeared in four of five top models for culpeo (including the best model) and was important for model fit for the culpeo but was not a significant driver of culpeo occupancy ( $\beta=-4.19, \mathrm{SE}=2.74)$.

Similarly, results varied in quantifying responses of native carnivore occupancy to dog presence. For chilla, dog occupancy was not in the best chilla model but appeared as a positive driver in six of 10 top models, which had comparable weights to the best model (Table 1). The dog occupancy covariate was not influential, positive or negative, on occupancy for güiña. Culpeo was the only species with dog occupancy in the top model with a negative (non-significant) $\beta$ coefficient. The dog landscape-level occupancy from the top model was 0.58 . Increasing dog occupancy to 0.65 (an increase of $12.1 \%$ ) resulted in dog occupancy becoming a significant negative driver of culpeo occupancy (Figure S1.1).

We found no evidence for the interaction of dog occupancy and understorey affecting occupancy for native mesocarnivore species occupancy. Overall, we conclude that landscape characteristics via metrics of increasing fragmentation have similar positive effects for both generalist native carnivores and dogs (Figure 4). 


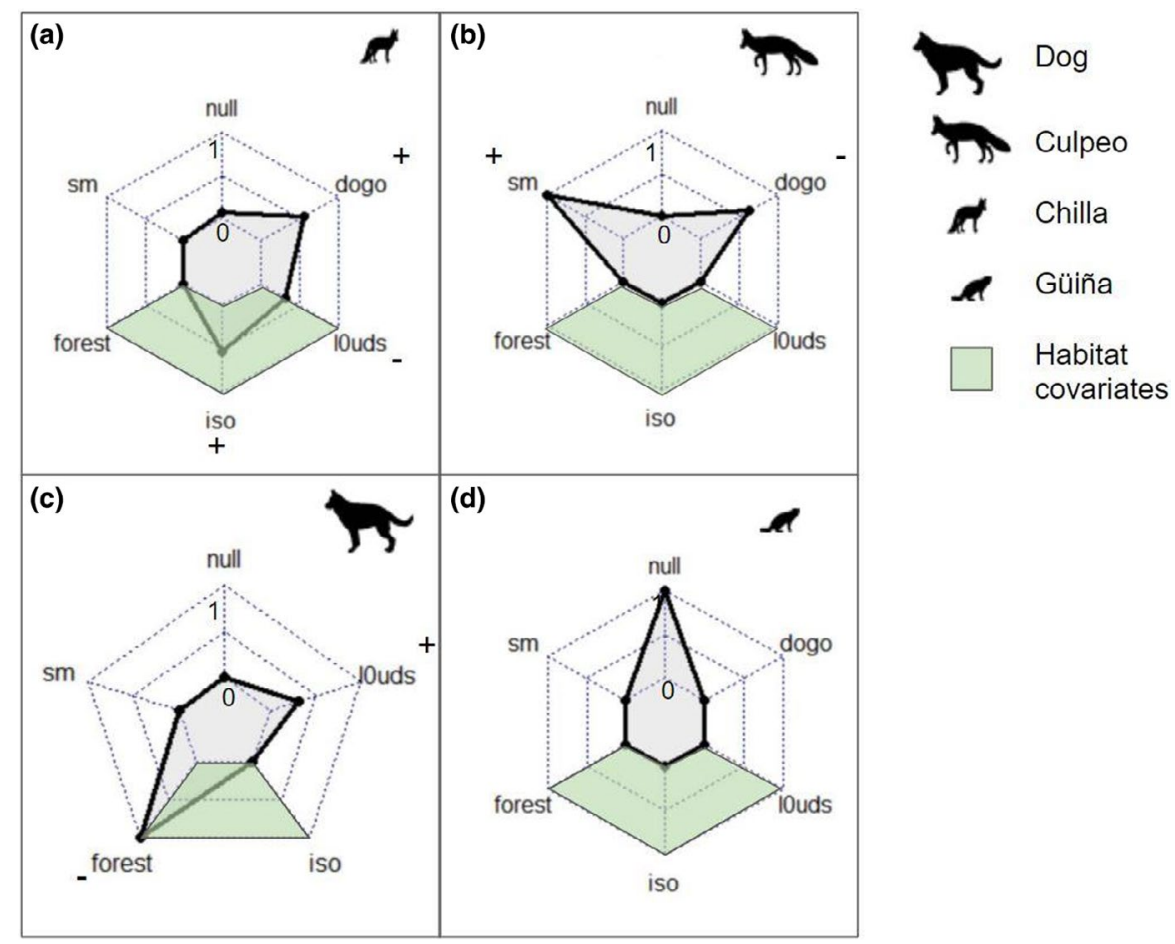

FIGURE 4 Relative importance of each covariate on species occupancy based on summed model weights for top model sets ( $<2 \Delta$ AICc/ QAICc). dogo: dog occupancy; cam: camera type; 10uds: average understorey height within $10 \mathrm{~m}$; iso: average distance between patches; forest: proportion native forest; sm: small mammal trap success. Beta coefficients for each covariate were averaged across the top model set. (a) Dog occupancy and patch isolation were positively correlated with chilla occupancy, while understorey was negatively correlated; (b) small mammal trap success was positively correlated with culpeo occupancy, while dog occupancy was negatively correlated; (c) proportion of native forest was negatively correlated with dog occupancy, while understorey was positively correlated; (d) güiña occupancy was best described by the null model

\section{3 | Temporal activity}

We evaluated temporal activity patterns of all our study species to determine whether there was evidence for temporal avoidance with dogs (Fig. S1.2). Activity patterns for the three native carnivores were largely restricted to the nocturnal and crepuscular hours. Overlap among the native carnivores was high ( $\Delta$ ranging from 0.78 to 0.89 ) and did not vary significantly among pairs (Table 3: $p$ values: .08-.79). In contrast, dog activity was almost entirely diurnal, resulting in significantly different activity patterns from native species $(\Delta$ ranging from 0.35 to $0.43, p<.001$ ). Furthermore, $95 \%$ confidence intervals for $\Delta$ dog-native species pairs and for $\Delta$ native-native species pairs did not overlap in a single case, indicating that native species overlapped significantly more with other native species than they did with dogs.

\section{DISCUSSION}

The threats that mammals face from habitat loss and fragmentation are especially relevant in the context of the temperate rain forests of central Chile, which have included rapid deforestation and fragmentation in the past 50 years (Echeverría et al., 2006, 2008; Nahuelhual et al., 2012; Uribe et al., 2020). An additional human-related threat is the presence of dogs, which antagonize native species and preferentially use the matrix that separates the remaining patches (SilvaRodríguez, Ortega-Solís, et al., 2010). Using single-species models, we investigated the impacts of these two phenomena (habitat destruction and dogs) on the occupancy of three native carnivores (foxes:chilla and culpeo; cat:güiña), in remnant forest patches within an agricultural matrix. Our results varied by species, indicating that components of habitat destruction have opposing effects for the two foxes, as do dogs. For dogs, we found evidence that occupancy increases with habitat loss. Time use of all native species was concentrated during the nocturnal period, in stark contrast to the diurnal time use of the dog. Our results provide the necessary baseline to understand dogs and habitat destruction metrics as drivers of native species occupancy and could be further expanded to multispecies models to examine species interactions.

For the species included in this study, at first glance our results suggest that landscape degradation does not pose an immediate concern. For the chilla, the positive correlation between patch isolation and occupancy is likely a reflection of the ecology of the fox, which primarily forages in the open fields that comprise the matrix between patches (Silva-Rodríguez, Ortega-Solís, et al., 2010). However, this species also uses interior habitat of these patches as a refuge and thus, would likely have negative consequences if patches fell below a threshold size (Silva-Rodríguez, Ortega-Solís, et al., 2010). 
TABLE 1 Top occupancy $(\Psi)$ and detection $(p)$ models for native carnivore and dogs ranked by AICc with model weights $(w)$

\begin{tabular}{|c|c|c|c|c|}
\hline Species & Top models & $\mathrm{AICc}$ & $\triangle \mathrm{AlCc}^{\mathrm{a}}$ & $w$ \\
\hline \multirow[t]{10}{*}{ Chilla } & $\Psi$ (iso) $p$ (dogo, 10uds) & 429.809 & 0 & 0.175 \\
\hline & $\Psi$ (iso) p(dogo, 10uds, cam) & 430.289 & 0.480 & 0.138 \\
\hline & $\Psi($ dogo) $p$ (dogo, 10uds) & 430.613 & 0.804 & 0.117 \\
\hline & $\Psi$ (dogo, 10uds) p(dogo, 10uds) & 430.782 & 0.974 & 0.108 \\
\hline & $\Psi($ dogo $) p($ dogo, 10 uds, cam $)$ & 430.948 & 1.139 & 0.099 \\
\hline & $\Psi$ (iso, dogo) $p$ (dogo, 10uds) & 431.139 & 1.331 & 0.090 \\
\hline & $\begin{array}{l}\Psi \text { (dogo, 10uds) } p \text { (dogo, 10uds, } \\
\text { cam) }\end{array}$ & 431.511 & 1.702 & 0.075 \\
\hline & $\Psi$ (iso, 10uds) p(dogo, 10uds) & 431.736 & 1.927 & 0.067 \\
\hline & $\Psi(\sim 1) p($ dogo, 10uds) & 431.738 & 1.929 & 0.067 \\
\hline & $\begin{array}{l}\Psi \text { (iso, dogo, 10uds) } p \text { (dogo, } \\
\text { 10uds) }\end{array}$ & 431.792 & 1.982 & 0.065 \\
\hline \multirow[t]{7}{*}{ Culpeo } & $\Psi($ dogo, sm) $p($ dogo, cam, 10uds) & 124.932 & 0 & 0.273 \\
\hline & $\Psi($ dogo, sm) p(dogo, 10uds) & 126.238 & 1.306 & 0.142 \\
\hline & $\Psi(\mathrm{sm})$ p(dogo, cam, 10uds) & 126.280 & 1.348 & 0.139 \\
\hline & $\Psi($ dogo, sm) p(dogo, cam) & 126.598 & 1.666 & 0.119 \\
\hline & $\Psi(\mathrm{sm}) p$ (dogo, trap, 10uds) & 126.734 & 1.802 & 0.111 \\
\hline & $\Psi(\mathrm{sm}) p$ (dogo, 10uds) & 126.753 & 1.821 & 0.110 \\
\hline & $\Psi($ dogo, sm) $p($ dogo, cam, trap) & 126.802 & 1.870 & 0.107 \\
\hline \multirow[t]{4}{*}{ Dog } & $\Psi$ (forest) $p$ (10uds, trap) & 272.000 & 0 & 0.370 \\
\hline & $\Psi($ forest $) p(10$ uds, trap, cam) & 272.306 & 0.306 & 0.318 \\
\hline & $\Psi$ (forest, 10uds) $p(10 u d s$, trap) & 273.704 & 1.704 & 0.158 \\
\hline & $\begin{array}{l}\Psi(\text { forest, 10uds) } p(10 u d s, \text { trap, } \\
\text { cam) }\end{array}$ & 273.757 & 1.757 & 0.154 \\
\hline Güiña & $\Psi(\sim 1) p(\sim 1)$ & 6.830 & 0 & 0.101 \\
\hline
\end{tabular}

Abbreviations: 10uds, average understorey height within $10 \mathrm{~m}$; cam, camera type; dogo, dog occupancy; forest, proportion native forest; iso, average distance between patches; sm, small mammal trap success.

${ }^{a}$ QAICc was used instead of AICc in model ranking for güiña occupancy to account for overdispersion of the global model.
Our results for culpeos and güiñas, which did not show any response to either habitat loss or patch isolation, could indicate that: (a) these species are plastic in their habitat requirements; (b) fragmentation and habitat loss have not reached a sufficient threshold to elicit a response; (c) there is a time-lagged "extinction debt"; or (d) these species are tracking spatial patterns of prey, predator or competitor species instead (Halley et al., 2016; Hanski \& Ovaskainen, 2002; Ryall \& Fahrig, 2006; Swift \& Hannon, 2010). The model results for the culpeo suggested this latter mechanism, as they were positively driven by prey availability, and dog occupancy was consistent in the top models having a negative coefficient (though note that neither covariate was significant using a significance level of $\alpha=0.05$ ). While landscape characteristics did not appear as a negative driver in any native species models, the inverse relationship between dog occupancy and proportion of forest indicates as habitat loss increases in this region native species will have less refuge habitat to avoid exposure to domestic dogs (Paschoal et al., 2018; Torres \& Prado, 2010).

We expected dogs to influence native carnivore occupancy because of their documented impact on small carnivores through interference and exploitation competition, and the increased mortality risk they pose as disease reservoirs (Laurenson et al., 1998; Rhodes et al., 1998; Sillero-Zubiri et al., 2004; Vanak \& Gompper, 2009, 2010). Dogs have been linked to the decline of the pudu, a potential prey item for the two fox species in this study (Silva-Rodríguez \& Sieving, 2012). Despite the threat that a dog encounter presents, dog occupancy did not clearly present a negative driver of native species occupancy and only featured as a non-significant negative covariate for culpeo top models. While this partially fit our expectation that native canids would more likely have antagonistic interactions with dogs and exhibit avoidance, we expected the smaller chilla fox to have greater sensitivity to dog presence (Donadio \& Buskirk, 2006; Vanak \& Gompper, 2009). Previous studies corroborate this expectation as dogs enforce interference competition to alter space use and have been observed harassing and killing chilla (Silva-Rodríguez, Ortega-Solís, et al., 2010). A lack of a negative response from chillas to dogs using our occupancy framework could indicate that foxes were avoiding dogs at finer spatial or temporal scales or that dog density was not sufficiently high to elicit a spatial 
avoidance (Qi et al., 2020; Zapata-Ríos \& Branch, 2018). Indeed, our analysis of activity patterns suggests temporal partitioning as a mechanism for avoidance of dogs (Kronfeld-Schor \& Dayan, 2003; Schuette et al., 2013). In contrast to chillas, culpeos did indicate a potential response to dogs at a landscape level and showed no response to habitat loss and fragmentation. Our result for culpeo occupancy was consistent with that of Zapata-Ríos and Branch (2018), despite differences in the landscape histories between our formerly contiguously forested site and their historically patchy Andes site. Congruent with the dog occupancy estimates $(\Psi=0.66$, range: 0.53-0.73) from Zapata-Ríos and Branch (2018), it took a projected $12 \%$ increase in dog occupancy in our study site (from $\Psi=0.58$ ) for it to have a significant negative effect on culpeo occupancy.

While dogs had opposite effects on the occupancies of the fox species, they increased detection for both the culpeo and the chilla. Movement data for canids highlight quicker speeds through riskier areas, which would likely impact detection rates (Broadley et al., 2019; Péron et al., 2017). Thus, increased detection for the fox species may reflect a finer scale response to the risk posed by dogs, rather than a broader change in spatial use (Broekhuis et al., 2013). This interpretation, along with mismatched time use, would reconcile the open habitat preferences of the chilla fox with its increased susceptibility to dog antagonism based on size (Donadio \& Buskirk, 2006).

Fragmentation can facilitate the spread of invasive species through numerous pathways such as roads increasing the occurrence of dogs (Loss et al., 2013; Moreira-Arce et al., 2015). Yet, few occupancy studies explore the impacts of both dogs and habitat loss and fragmentation on native carnivores. Dogs are typically considered human-associated, though they may travel considerable distances and thus can impact the larger landscape (Gompper, 2013; Young et al., 2011). Furthermore, their space use, while tied to human impacts on the landscape, is more nuanced than simply being a result of nearby human habitation. In a North American system for example, dog occupancy has been found to increase with proportion forest (Morin et al., 2018), in contrast with our results that dog occupancy decreased marginally with proportion of forest. However, Morin et al. (2018) also found that pastures and grasslands were an even stronger positive predictor of dog occupancy; the land type that was the inverse of our measured metric for proportion forest. Whether the interaction between dogs and proportion forest impacts native carnivores can be intuitively answered when we see that dog occupancy can be a negative driver of culpeo occupancy if it surpasses a threshold. In "working" landscapes, this is particularly relevant as habitat loss and dog occupancy will likely continue to increase over time. Our occupancy results suggest that the spatial use of both fox species (indirectly in the case of the culpeo, through dog occupancy) is tied to fragmentation and habitat loss. Furthermore, habitat destruction in the landscape increases the exposure of both foxes to the threat of a dog encounter (Farris et al., 2017, 2020). In the currently remaining forest stands that we surveyed, the largely nocturnal temporal use of native species provides a likely avoidance mechanism (Gerber et al., 2012; Shores et al., 2019). 
TABLE 3 Overlap coefficients ( $\Delta$ ) and Mardia-Watson-Wheeler test for homogeneity of means for every pairwise combination of the study species. $\Delta_{4}$ was used for every comparison except for those pairs containing the culpeo, where $\Delta_{1}$ was used to account for lower number of triggers

\begin{tabular}{|llll} 
Comparison & $\begin{array}{l}\Delta \text { Overlap }(95 \% \\
\text { CI) }\end{array}$ & W statistic & $p$-value \\
\hline Chilla-dog & $0.40(0.25-0.44)$ & 83.62 & $<.001$ \\
\hline Culpeo-dog & $0.35(0.22-0.48)$ & 42.96 & $<.001$ \\
\hline Güiña-dog & $0.43(0.30-0.56)$ & 47.84 & .001 \\
\hline Chilla-culpeo & $0.78(0.66-0.89)$ & 5.02 & .08 \\
\hline Chilla- güiña & $0.89(0.80-0.97)$ & 0.47 & .79 \\
\hline Güiña-culpeo & $0.78(0.75-1.03)$ & 4.79 & .09 \\
\hline
\end{tabular}

Our study gives us insight into the drivers of native carnivore space use in "working" landscapes rather than the protected areas that historically represent ideal and untouched habitats. By situating our study on privately owned smallholder lands, we also have the unique opportunity to inform the conservation of species in these increasingly anthropogenic landscapes through local education efforts (Gramza et al., 2016). The remnant patches in these private lands may be particularly important for the persistence of native carnivores in the landscape, and in general, agricultural landscapes may hold considerable biodiversity and conservation value (Kremen \& Merenlender, 2018; Lindenmayer, 2019; Wintle et al., 2019). Many landowners do not have access to camera traps and thus, are unlikely to encounter elusive carnivores that are present even in small patches of forest along the edges of their pasturelands. While voluntary strategies for conservation have greater social acceptance than prescribed management action, they are not possible without landowners first having the knowledge of what species are on their land (Kamal et al., 2015). By partnering with landowners, scientists and managers can facilitate species conservation in these important landscapes, which are not typically considered conservation targets (Naugle et al., 2020). This partnership may yield dividends in collaboratively designing management solutions for dogs (Ford-Thompson et al., 2012). The management of domestic animals can be a source of intense debate, especially in regard to animals typically considered as pets (Wald et al., 2013). The impacts of dogs on wildlife is underestimated; conservation practitioners can learn from the intense controversy generated by the management of feral cats by involving local stakeholders, and by bringing a strong understanding of what factors drive the impacts of dogs on native carnivore species (Doherty et al., 2017; Loyd \& Miller, 2010).

\section{ACKNOWLEDGEMENTS}

Our work would not have been possible without the support of the many landowners who gave us permission to place cameras on their land, including K. Konrad, C. Konrad, W. Silva, M. Hinostroza, L. Miño, H. Beckhert, K. Beckhert, V. Beckhert and G. Weisser. We thank past and present members of the Applied Wildlife Ecology Lab, especially N.A. Arringdale for GIS support and K.L. Mills for feedback and edits on earlier drafts, as well as committe members C. Badgley, A.J. Marshall and J. Vandermeer for assistance with study design. We appreciate field support from M.A. Lyons in helping collect data and communicating in Spanish with landowners. In additional, this work would have been impossible without the support of M.I. Ramírez, who generously provided logistical support throughout the field season. Finally, we would like to thank the University of Michigan Latin American and Caribbean Association, the Rackham Graduate School, and the Ecology and Evolutionary Biology Department for funds, which made the data collection possible.

\section{CONFLICT OF INTEREST}

The authors do not have any conflicts of interest to declare.

\section{PEER REVIEW}

The peer review history for this article is available at https://publo ns.com/publon/10.1111/ddi.13391.

\section{DATA AVAILABILITY STATEMENT}

The data that support the findings of this study are openly available in Dryad at https://doi.org/10.5061/dryad.3xsj3txfv.

\section{ORCID}

Rumaan Malhotra (iD https://orcid.org/0000-0001-9656-094X

Jaime E. Jiménez iD https://orcid.org/0000-0002-9816-1149

Nyeema C. Harris iD https://orcid.org/0000-0001-5174-2205

\section{REFERENCES}

Agostinelli, C., \& Lund, U. (2017). R package 'circular': Circular Statistics (version 0.4-93). Retrieved from https://r-forge.r-project.org/proje cts/circular/

Bartlett, L. J., Newbold, T., Purves, D. W., Tittensor, D. P., \& Harfoot, M. B. J. (2016). Synergistic impacts of habitat loss and fragmentation on model ecosystems. Proceedings of the Royal Society B: Biological Sciences, 283, 20161027. https://doi.org/10.1098/rspb.2016.1027

Bennett, A. F., \& Saunders, D. A. (2010). Habitat fragmentation and landscape change. Conservation Biology for All, 93, 1544-1550.

Broadbent, E. N., Asner, G. P., Keller, M., Knapp, D. E., Oliveira, P. J. C., \& Silva, J. N. (2008). Forest fragmentation and edge effects from deforestation and selective logging in the Brazilian Amazon. Biological Conservation, 141, 1745-1757. https://doi.org/10.1016/j.biocon.2008.04.024

Broadley, K., Burton, A. C., Avgar, T., \& Boutin, S. (2019). Densitydependent space use affects interpretation of camera trap detection rates. Ecology and Evolution, 9, 14031-14041. https://doi. org/10.1002/ece3.5840

Broekhuis, F., Cozzi, G., Valeix, M., McNutt, J. W., \& Macdonald, D. W. (2013). Risk avoidance in sympatric large carnivores: Reactive or predictive? Journal of Animal Ecology, 82, 1098-1105. https://doi. org/10.1111/1365-2656.12077

Climate-Data.org. (n.d.). Osorno climate: Average Temperature, weather by month, Osorno weather averages. Retrieved from https://en.climatedata.org/south-america/chile/x-region-de-los-lagos/osorno-2047/

Cochrane, M. A. (2001). Synergistic interactions between habitat fragmentation and fire in evergreen tropical forests. Conservation Biology, 15, 1515-1521. https://doi.org/10.1046/j.1523-1739.2001.01091.x

Crooks, K. R. (2002). Relative sensitivities of mammalian carnivores to habitat fragmentation. Conservation Biology, 16, 488-502. https:// doi.org/10.1046/j.1523-1739.2002.00386.x 
Crooks, K. R., Burdett, C. L., Theobald, D. M., King, S. R. B., Di Marco, M., Rondinini, C., \& Boitani, L. (2017). Quantification of habitat fragmentation reveals extinction risk in terrestrial mammals. Proceedings of the National Academy of Sciences of the United States of America, 114, 7635-7640. https://doi.org/10.1073/pnas.1705769114

Doherty, T. S., Dickman, C. R., Glen, A. S., Newsome, T. M., Nimmo, D. G., Ritchie, E. G., Vanak, A. T., \& Wirsing, A. J. (2017). The global impacts of domestic dogs on threatened vertebrates. Biological Conservation, 210, 56-59. https://doi.org/10.1016/j.biocon.2017.04.007

Donadio, E., \& Buskirk, S. W. (2006). Diet, morphology, and interspecific killing in Carnivora. The American Naturalist, 167, 524-536. https:// doi.org/10.1086/501033

Echeverria, C., Coomes, D. A., Hall, M., \& Newton, A. C. (2008). Spatially explicit models to analyze forest loss and fragmentation between 1976 and 2020 in southern Chile. Ecological Modelling, 212, 439-449. https://doi.org/10.1016/j.ecolmodel.2007.10.045

Echeverria, C., Coomes, D., Salas, J., Rey-Benayas, J. M., Lara, A., \& Newton, A. (2006). Rapid deforestation and fragmentation of Chilean Temperate Forests. Biological Conservation, 130, 481-494. https://doi.org/10.1016/j.biocon.2006.01.017

Echeverría, C., Newton, A. C., Lara, A., Benayas, J. M. R., \& Coomes, D. A. (2007). Impacts of forest fragmentation on species composition and forest structure in the temperate landscape of southern Chile. Global Ecology and Biogeography, 16, 426-439. https://doi. org/10.1111/j.1466-8238.2007.00311.x

Echeverría, C., Newton, A., Nahuelhual, L., Coomes, D., \& Rey-Benayas, J. M. (2012). How landscapes change: Integration of spatial patterns and human processes in temperate landscapes of southern Chile. Applied Geography, 32, 822-831. https://doi.org/10.1016/j. apgeog.2011.08.014

Fahrig, L. (2013). Rethinking patch size and isolation effects: The habitat amount hypothesis. Journal of Biogeography, 40, 1649-1663. https:// doi.org/10.1111/jbi.12130

Fahrig, L., Arroyo-Rodríguez, V., Bennett, J. R., Boucher-Lalonde, V., Cazetta, E., Currie, D. J., Eigenbrod, F., Ford, A. T., Harrison, S. P., Jaeger, J. A. G., Koper, N., Martin, A. E., Martin, J.-L., Metzger, J. P., Morrison, P., Rhodes, J. R., Saunders, D. A., Simberloff, D., Smith, A. C., ... Watling, J. I. (2019). Is habitat fragmentation bad for biodiversity? Biological Conservation, 230, 179-186. https://doi. org/10.1016/j.biocon.2018.12.026

Farris, Z. J., Gerber, B. D., Karpanty, S., Murphy, A., Wampole, E., Ratelolahy, F., \& Kelly, M. J. (2020). Exploring and interpreting spatiotemporal interactions between native and invasive carnivores across a gradient of rainforest degradation. Biological Invasions, 22, 20332047. https://doi.org/10.1007/s10530-020-02237-1

Farris, Z. J., Gerber, B.D., Valenta, K., Rafaliarison, R., Razafimahaimodison, J. C., Larney, E., Rajaonarivelo, T., Randriana, Z., Wright, P. C., \& Chapman, C. A. (2017). Threats to a rainforest carnivore community: A multi-year assessment of occupancy and co-occurrence in Madagascar. Biological Conservation, 210, 116-124. https://doi. org/10.1016/j.biocon.2017.04.010

Farris, Z. J., Kelly, M. J., Karpanty, S., \& Ratelolahy, F. (2016). Patterns of spatial co-occurrence among native and exotic carnivores in northeastern Madagascar. Animal Conservation, 19, 189-198. https://doi. org/10.1111/acv.12233

Fiske, I., \& Chandler, R. (2011). Unmarked: An R package for fitting hierarchical models of wildlife occurrence and abundance. Journal of Statistical Software, 43, 1-23.

Fletcher, R. J., Didham, R. K., Banks-Leite, C., Barlow, J., Ewers, R. M., Rosindell, J., Holt, R. D., Gonzalez, A., Pardini, R., Damschen, E. I., Melo, F. P. L., Ries, L., Prevedello, J. A., Tscharntke, T., Laurance, W. F., Lovejoy, T., \& Haddad, N. M. (2018). Is habitat fragmentation good for biodiversity? Biological Conservation, 226, 9-15. https://doi. org/10.1016/j.biocon.2018.07.022
Ford-Thompson, A. E. S., Snell, C., Saunders, G., \& White, P. C. L. (2012). Stakeholder participation in management of invasive vertebrates. Conservation Biology, 26, 345-356. https://doi. $\operatorname{org} / 10.1111 / \mathrm{j} .1523-1739.2011 .01819 . x$

Gerber, B. D., Karpanty, S. M., \& Randrianantenaina, J. (2012). Activity patterns of carnivores in the rain forests of Madagascar: Implications for species coexistence. Journal of Mammalogy, 93, 667-676. https:// doi.org/10.1644/11-MAMM-A-265.1

Gompper, M. E. (2013). Free-ranging dogs and wildlife conservation. Oxford University Press.

Gramza, A., Teel, T., VandeWoude, S., \& Crooks, K. (2016). Understanding public perceptions of risk regarding outdoor pet cats to inform conservation action. Conservation Biology, 30, 276-286. https://doi. org/10.1111/cobi.12631

Haddad, N. M., Brudvig, L. A., Clobert, J., Davies, K. F., Gonzalez, A., Holt, R. D., Lovejoy, T. E., Sexton, J. O., Austin, M. P., Collins, C. D., Cook, W. M., Damschen, E. I., Ewers, R. M., Foster, B. L., Jenkins, C. N., King, A. J., Laurance, W. F., Levey, D. J., Margules, C. R., ... Townshend, J. R. (2015). Habitat fragmentation and its lasting impact on Earth's ecosystems. Science Advances, 1, e1500052. https://doi.org/10.1126/sciadv.1500052

Halley, J. M., Monokrousos, N., Mazaris, A. D., Newmark, W. D., \& Vokou, D. (2016). Dynamics of extinction debt across five taxonomic groups. Nature Communications, 7, 12283. https://doi.org/10.1038/ncomm s12283

Hanski, I., \& Ovaskainen, O. (2002). Extinction debt at extinction threshold. Conservation Biology, 16, 666-673. https://doi. org/10.1046/j.1523-1739.2002.00342.x

Harrison, M. L. K., \& Banks-Leite, C. (2020). Edge effects on trophic cascades in tropical rainforests. Conservation Biology, 34, 977-987. https://doi.org/10.1111/cobi.13438

Hughes, J., \& Macdonald, D. W. (2013). A review of the interactions between free-roaming domestic dogs and wildlife. Biological Conservation, 157, 341-351. https://doi.org/10.1016/j. biocon.2012.07.005

Janecka, J. E., Tewes, M. E., Davis, I. A., Haines, A. M., Caso, A., Blankenship, T. L., \& Honeycutt, R. L. (2016). Genetic differences in the response to landscape fragmentation by a habitat generalist, the bobcat, and a habitat specialist, the ocelot. Conservation Genetics, 17, 1093-1108. https://doi.org/10.1007/s10592-016-0846-1

Jessen, T., Wang, Y., \& Wilmers, C. C. (2018). Habitat fragmentation provides a competitive advantage to an invasive tree squirrel, Sciurus carolinensis. Biological Invasions, 20, 607-618. https://doi.org/10.1007/ s10530-017-1560-8

Kamal, S., Grodzińska-Jurczak, M., \& Brown, G. (2015). Conservation on private land: A review of global strategies with a proposed classification system. Journal of Environmental Planning and Management, 58, 576-597. https://doi.org/10.1080/09640568.2013.875463

Karl, J. W., McCord, S. E., \& Hadley, B. C. (2017). A comparison of cover calculation techniques for relating point-intercept vegetation sampling to remote sensing imagery. Ecological Indicators, 73, 156-165. https://doi.org/10.1016/j.ecolind.2016.09.034

Kremen, C., \& Merenlender, A. M. (2018). Landscapes that work for biodiversity and people. Science, 362, eaau6020. https://doi.org/10.1126/ science.aau6020

Kronfeld-Schor, N., \& Dayan, T. (2003). Partitioning of time as an ecological resource. Annual Review of Ecology, Evolution, and Systematics, 34, 153-181. https://doi.org/10.1146/annurev.ecolsys.34.011802.132435

Laurenson, K., Sillero-Zubiri, C., Thompson, H., Shiferaw, F., Thirgood, S., \& Malcolm, J. (1998). Disease as a threat to endangered species: Ethiopian wolves, domestic dogs and canine pathogens. Animal Conservation, 1,273-280. https://doi.org/10.1111/j.1469-1795.1998. tb00038.x

Lindenmayer, D. (2019). Small patches make critical contributions to biodiversity conservation. Proceedings of the National Academy of 
Sciences of the United States America, 116, 717-719. https://doi. org/10.1073/pnas.1820169116

Loss, S. R., Will, T., \& Marra, P. P. (2013). The impact of free-ranging domestic cats on wildlife of the United States. Nature Communications, 4, 1396.

Loyd, K. A., \& Miller, C. A. (2010). Factors related to preferences for trap-neuter-release management of feral cats among Illinois homeowners. The Journal of Wildlife Management, 74, 160-165. https://doi. org/10.2193/2008-488

MacKenzie, D. I., Nichols, J. D., Hines, J. E., Knutson, M. G., \& Franklin, A. B. (2003). Estimating site occupancy, colonization, and local extinction when a species is detected imperfectly. Ecology, 84, 2200-2207. https://doi.org/10.1890/02-3090

MacKenzie, D. I., Nichols, J. D., Royle, J. A., Pollock, K. H., Bailey, L., \& Hines, J. E. (2017). Occupancy estimation and modeling: Inferring patterns and dynamics of species occurrence. Amsterdam: Elsevier.

Massara, R. L., Paschoal, A. M. O., Bailey, L. L., Doherty, P. F., \& Chiarello, A. G. (2016). Ecological interactions between ocelots and sympatric mesocarnivores in protected areas of the Atlantic Forest, southeastern Brazil. Journal of Mammalogy, 97, 1634-1644. https://doi. org/10.1093/jmammal/gyw129

Michel, V. T., Jiménez-Franco, M. V., Naef-Daenzer, B., \& Grüebler, M. U. (2016). Intraguild predator drives forest edge avoidance of a mesopredator. Ecosphere, 7, e01229. https://doi.org/10.1002/ecs2.1229

Montibeller, B., Kmoch, A., Virro, H., Mander, Ü., \& Uuemaa, E. (2020). Increasing fragmentation of forest cover in Brazil's Legal Amazon from 2001 to 2017. Scientific Reports, 10, 5803. https://doi. org/10.1038/s41598-020-62591-x

Moreira-Arce, D., Vergara, P. M., \& Boutin, S. (2015). Diurnal human activity and introduced species affect occurrence of carnivores in a human-dominated landscape. PLoS One, 10, e0137854. https://doi. org/10.1371/journal.pone.0137854

Morin, D. J., Lesmeister, D. B., Nielsen, C. K., \& Schauber, E. M. (2018). The truth about cats and dogs: Landscape composition and human occupation mediate the distribution and potential impact of nonnative carnivores. Global Ecology and Conservation, 15, e00413. https://doi.org/10.1016/j.gecco.2018.e00413

Myers, N., Mittermeier, R. A., Mittermeier, C. G., Da Fonseca, G. A., \& Kent, J. (2000). Biodiversity hotspots for conservation priorities. Nature, 403, 853. https://doi.org/10.1038/35002501

Nahuelhual, L., Carmona, A., Lara, A., Echeverría, C., \& González, M. E. (2012). Land-cover change to forest plantations: Proximate causes and implications for the landscape in south-central Chile. Landscape and Urban Planning, 107, 12-20. https://doi.org/10.1016/j.landu rbplan.2012.04.006

Naugle, D. E., Allred, B. W., Jones, M. O., Twidwell, D., \& Maestas, J. D. (2020). Coproducing science to inform working lands: The next frontier in nature conservation. BioScience, 70, 90-96. https://doi. org/10.1093/biosci/biz144

Niedballa, J., Sollmann, R., Courtiol, A., \& Wilting, A. (2016). camtrapR: An $\mathrm{R}$ package for efficient camera trap data management. Methods in Ecology and Evolution, 7, 1457-1462. https://doi. org/10.1111/2041-210X.12600

Oehler, J. D., \& Litvaitis, J. A. (1996). The role of spatial scale in understanding responses of medium-sized carnivores to forest fragmentation. Canadian Journal of Zoology, 74, 2070-2079. https://doi. org/10.1139/z96-235

Palmeirim, A. F., Santos-Filho, M., \& Peres, C. A. (2020). Marked decline in forest-dependent small mammals following habitat loss and fragmentation in an Amazonian deforestation frontier. PLoS One, 15, e0230209. https://doi.org/10.1371/journal.pone.0230209

Palomares, F., \& Caro, T. M. (1999). Interspecific killing among mammalian carnivores. The American Naturalist, 153, 492-508. https://doi. org/10.1086/303189
Paschoal, A. M. O., Massara, R. L., Bailey, L. L., Doherty, P. F., Santos, P. M., Paglia, A. P., Hirsch, A., \& Chiarello, A. G. (2018). Anthropogenic disturbances drive domestic dog use of Atlantic forest protected areas. Tropical Conservation Science, 11, 1940082918789833. https://doi. org/10.1177/1940082918789833

Peres, C. A. (2001). Synergistic effects of subsistence hunting and habitat fragmentation on Amazonian forest vertebrates. Conservation Biology, 15, 1490-1505. https://doi.org/10.1046/j.1523-1739.2001.01089.x

Péron, G., Fleming, C. H., de Paula, R. C., Mitchell, N., Strohbach, M., Leimgruber, P., \& Calabrese, J. M. (2017). Periodic continuous-time movement models uncover behavioral changes of wild canids along anthropization gradients. Ecological Monographs, 87, 442-456. https://doi.org/10.1002/ecm.1260

Pfeifer, M., Lefebvre, V., Peres, C. A., Banks-Leite, C., Wearn, O. R., Marsh, C. J., Butchart, S. H. M., Arroyo-Rodríguez, V., Barlow, J., Cerezo, A., Cisneros, L., D'Cruze, N., Faria, D., Hadley, A., Harris, S. M., Klingbeil, B. T., Kormann, U., Lens, L., Medina-Rangel, G. F., ... Ewers, R. M. (2017). Creation of forest edges has a global impact on forest vertebrates. Nature, 551, 187-191. https://doi.org/10.1038/ nature24457

Qi, J., Holyoak, M., Ning, Y., \& Jiang, G. (2020). Ecological thresholds and large carnivores conservation: Implications for the Amur tiger and leopard in China. Global Ecology and Conservation, 21, e00837. https://doi.org/10.1016/j.gecco.2019.e00837

Randa, L. A., \& Yunger, J. A. (2006). Carnivore occurrence along an urbanrural gradient: A landscape-level analysis. Journal of Mammalogy, 87, 1154-1164. https://doi.org/10.1644/05-MAMM-A-224R2.1

R Development Core Team. (2019). R: A Language and Environment for Statistical Computing. Vienna, Austria: R Foundation for Statistical Computing.

Rhodes, C., Atkinson, R., Anderson, R., \& Macdonald, D. (1998). Rabies in Zimbabwe: Reservoir dogs and the implications for disease control. Philosophical Transactions of the Royal Society of London. Series B: Biological Sciences, 353, 999-1010. https://doi.org/10.1098/ rstb.1998.0263

Ridout, M. S., \& Linkie, M. (2009). Estimating overlap of daily activity patterns from camera trap data. Journal of Agricultural, Biological, and Environmental Statistics, 14, 322-337.

Rielly-Carroll, E., \& Freestone, A. L. (2017). Habitat fragmentation differentially affects trophic levels and alters behavior in a multi-trophic marine system. Oecologia, 183, 899-908. https://doi.org/10.1007/ s00442-016-3791-2

Rocha, D. G., de Barros Ferraz, K. M. P. M., Gonçalves, L., Tan, C. K. W., Lemos, F. G., Ortiz, C., Peres, C. A., Negrões, N., Antunes, A. P., Rohe, F., Abrahams, M., Zapata-Rios, G., Teles, D., Oliveira, T., von Mühlen, E. M., Venticinque, E., Gräbin, D. M., Mosquera, B. D., Blake, J., ... Sollmann, R. (2020). Wild dogs at stake: Deforestation threatens the only Amazon endemic canid, the short-eared dog (Atelocynus microtis). Royal Society Open Science, 7, 190717.

Ryall, K. L., \& Fahrig, L. (2006). Response of predators to loss and fragmentation of prey habitat: A review of theory. Ecology, 87, 1086-1093.

Santos, F., Carbone, C., Wearn, O. R., Rowcliffe, J. M., Espinosa, S., Lima, M. G. M., Ahumada, J. A., Gonçalves, A. L. S., Trevelin, L. C., AlvarezLoayza, P., Spironello, W. R., Jansen, P. A., Juen, L., \& Peres, C. A. (2019). Prey availability and temporal partitioning modulate felid coexistence in Neotropical forests. PLoS One, 14, e0213671. https:// doi.org/10.1371/journal.pone.0213671

Schipper, J., Chanson, J. S., Chiozza, F., Cox, N. A., Hoffmann, M., Katariya, V., Lamoreux, J., Rodrigues, A. S. L., Stuart, S. N., Temple, H. J., Baillie, J., Boitani, L., Lacher, T. E., Mittermeier, R. A., Smith, A. T., Absolon, D., Aguiar, J. M., Amori, G., Bakkour, N., ... Young, B. E. (2008). The status of the world's land and marine mammals: Diversity, threat, and knowledge. Science, 322, 225-230. https://doi.org/10.1126/scien ce.1165115 
Schuette, P., Wagner, A. P., Wagner, M. E., \& Creel, S. (2013). Occupancy patterns and niche partitioning within a diverse carnivore community exposed to anthropogenic pressures. Biological Conservation, 158, 301-312. https://doi.org/10.1016/j.biocon.2012.08.008

Shores, C. R., Dellinger, J. A., Newkirk, E. S., Kachel, S. M., \& Wirsing, A. J. (2019). Mesopredators change temporal activity in response to a recolonizing apex predator. Behavioral Ecology, 30, 1324-1335. https:// doi.org/10.1093/beheco/arz080

Sillero-Zubiri, C., Hoffmann, M., \& Macdonald, D. W. (2004). Canids: Foxes, wolves, jackals, and dogs: Status survey and conservation action plan. IUCN.

Silva-Rodríguez, E., Farias, A., Moreira-Arce, D., Cabello, J., HidalgoHermoso, E., Lucherini, M., \& Jiménez, J. (2016). Lycalopex fulvipes. The IUCN Red List of Threatened Species, 2016, e.T41586A85370871.

Silva-Rodríguez, E. A., Ortega-Solís, G. R., \& Jiménez, J. E. (2010). Conservation and ecological implications of the use of space by chilla foxes and free-ranging dogs in a human-dominated landscape in southern Chile: Interference of chilla foxes by dogs in Chile. Austral Ecology, 35, 765-777. https://doi.org/10.1111/j.1442-9993.2009.02083.x

Silva-Rodríguez, E. A., \& Sieving, K. E. (2012). Domestic dogs shape the landscape-scale distribution of a threatened forest ungulate. Biological Conservation, 150, 103-110. https://doi.org/10.1016/j. biocon.2012.03.008

Silva-Rodríguez, E. A., Verdugo, C., Aleuy, O. A., Sanderson, J. G., Ortega-Solís, G. R., Osorio-Zúñiga, F., \& González-Acuña, D. (2010). Evaluating mortality sources for the Vulnerable pudu Pudu puda in Chile: Implications for the conservation of a threatened deer. Oryx, 44, 97-103. https://doi.org/10.1017/S0030605309990445

Smith, J. A., Duane, T. P., \& Wilmers, C. C. (2019). Moving through the matrix: Promoting permeability for large carnivores in a humandominated landscape. Landscape and Urban Planning, 183, 50-58. https://doi.org/10.1016/j.landurbplan.2018.11.003

Smith-Ramírez, C. (2004). The Chilean coastal range: A vanishing center of biodiversity and endemism in South American temperate rainforests. Biodiversity and Conservation, 13, 373-393. https://doi. org/10.1023/B:BIOC.0000006505.67560.9f

Smith-Ramirez, C., Celis-Diez, J. L., von Jenstchyk, E., Jimenez, J. E., Armesto, J. J., Smith-Ramirez, C., Celis-Diez, J. L., von Jenstchyk, E., Jimenez, J. E., \& Armesto, J. J. (2010). Habitat use of remnant forest habitats by the threatened arboreal marsupial Dromiciops gliroides (Microbiotheria) in a rural landscape of southern Chile. Wildlife Research, 37, 249-254. https://doi.org/10.1071/WR09050

Swift, T. L., \& Hannon, S. J. (2010). Critical thresholds associated with habitat loss: A review of the concepts, evidence, and applications. Biological Reviews, 85, 35-53. https://doi.org/10.1111/j.1469-185X.2009.00093.x

Torres, P. C., \& Prado, P. I. (2010). Domestic dogs in a fragmented landscape in the Brazilian Atlantic Forest: Abundance, habitat use and caring by owners. Brazilian Journal of Biology, 70, 987-994. https:// doi.org/10.1590/S1519-69842010000500010

Uribe, S. V., Estades, C. F., \& Radeloff, V. C. (2020). Pine plantations and five decades of land use change in central Chile. PLoS One, 15, e0230193. https://doi.org/10.1371/journal.pone.0230193

Vanak, A. T., \& Gompper, M. E. (2009). Dogs Canis familiaris as carnivores: Their role and function in intraguild competition. Mammal Review, 39, 265-283.

Vanak, A. T., \& Gompper, M. E. (2010). Interference competition at the landscape level: The effect of free-ranging dogs on a native mesocarnivore. Journal of Applied Ecology, 47, 1225-1232. https://doi. org/10.1111/j.1365-2664.2010.01870.x
Vanak, A. T., Thaker, M., \& Gompper, M. E. (2009). Experimental examination of behavioural interactions between free-ranging wild and domestic canids. Behavioral Ecology and Sociobiology, 64, 279-287. https://doi.org/10.1007/s00265-009-0845-z

Wald, D. M., Jacobson, S. K., \& Levy, J. K. (2013). Outdoor cats: Identifying differences between stakeholder beliefs, perceived impacts, risk and management. Biological Conservation, 167, 414-424. https://doi.org/10.1016/j.biocon.2013.07.034

Wintle, B. A., Kujala, H., Whitehead, A., Cameron, A., Veloz, S., Kukkala, A., Moilanen, A., Gordon, A., Lentini, P. E., Cadenhead, N. C. R., \& Bekessy, S. A. (2019). Global synthesis of conservation studies reveals the importance of small habitat patches for biodiversity. Proceedings of the National Academy of Sciences of the United States of America, 116, 909-914. https://doi.org/10.1073/pnas.1813051115

Young, J. K., Olson, K. A., Reading, R. P., Amgalanbaatar, S., \& Berger, J. (2011). Is wildlife going to the dogs? Impacts of feral and freeroaming dogs on wildlife populations. BioScience, 61, 125-132. https://doi.org/10.1525/bio.2011.61.2.7

Zapata-Ríos, G., \& Branch, L. C. (2018). Mammalian carnivore occupancy is inversely related to presence of domestic dogs in the high Andes of Ecuador. PLoS One, 13, e0192346. https://doi.org/10.1371/journ al.pone.0192346

\section{BIOSKETCH}

RM explores how anthropogenic pressures alter species interactions. More specifically, he is interested in how fragmentation alters native carnivore movement (short time-scales) and occupancy (longer time-scale), and how this translates to the community level.

JEJ examines the population and community ecology of mammals and birds with conservation concern in southern South America and Texas. More recently, he added the impacts of exotic mammals on local biotas, dispersal ecology and the biogeography of tardigrades. http://jaimeejimenez.com

$\mathrm{NCH}$ explores the antagonisms in nature, focusing on competition, predation and parasitism in mammalian systems. She links these research themes with anthropogenic pressures such as human-wildlife interactions to inform the conservation of large carnivores.

\section{SUPPORTING INFORMATION}

Additional supporting information may be found online in the Supporting Information section.

How to cite this article: Malhotra, R., Jiménez, J. E., \& Harris, N. C. (2021). Patch characteristics and domestic dogs differentially affect carnivore space use in fragmented landscapes in southern Chile. Diversity and Distributions, 00, 1-14. https://doi.org/10.1111/ddi.13391 